$\begin{array}{lll}\text { KULTURA } & \begin{array}{l}\text { POLSKA AKADEMIA NAUK } \\ \text { KOMITET SOCJOLOGII }\end{array} & \text { ISSN 0023-5172 } \\ { } } & \begin{array}{l}\text { INSTYTUT ST UDIÓW POLITYCZNYCH } \\ \text { SPOLECLENSTWO }\end{array} & \\ 2011, \text { nr 2-3 SOCJOLOGIA KULTURY }\end{array}$

ANDRZEJ SZPOCIŃSKI

Instytut Studiów Politycznych PAN

\title{
ANTONINY KŁOSKOWSKIEJ KONCEPCJA KULTURY NARODOWEJ JAKO ŹRÓDŁO INSPIRACJI
}

W pracach Antoniny Kłoskowskiej problematyka kultury narodowej stanowi integralną cześć rozważań nad narodem. „Naród w przeciwieństwie do państwa - pisze uczona (Kłoskowska 1996, s. 24) - jest zbiorowością społeczną o charakterze kulturowej wspólnoty. To określenie może posłużyć jako najkrótsza i wstępna jego definicja". Przy takim ujęciu wyczerpujące przedstawienie jej koncepcji kultury narodowej z konieczności musiałoby obejmować również poglądy na temat narodu i procesów narodotwórczych, a to zbyt dużo jak na jeden artykuł. Celem, jaki sobie tu stawiam, nie jest zatem wyczerpujące omówienie tej koncepcji. Chcę jedynie potraktować ją jako źródło inspiracji (tych, które wydały mi się najciekawsze) do badań nad kulturą w kontekście zmian $\mathrm{w}$ zachodzących $\mathrm{w}$ funkcjonowaniu współczesnych wspólnot narodowych. Zaproponowane przez Kłoskowską ujęcie kultury narodowej może być w tym bardzo pomocne. W czasach gorących dysput nad kondycją współczesnych narodów ulegających daleko idącym transformacjom pozwala ono na operacjonalizację zadań badawczych, a tym samym na dopełnienie dominujących we współczesnej humanistyce dywagacji, opartych na intuicji i obserwacji, systematycznymi badaniami socjologicznymi. Zacznę jednak od przypomnienia podstawowych tez wskazanej koncepcji.

Kultura narodowa rozumiana jest przez Kłoskowską jako część uniwersum kulturowego, a uniwersum kulturowe w jej ujęciu to suma ogólnoludzkich systemów symbolicznych, takich jak język, sztuka i literatura, wiedza i nauka, religia, obyczaje. Kształtowanie się uniwersum kulturowego jest uwarunkowane mechanizmami wynikającymi z gatunkowych zdolności człowieka do tworzenia systemów symbolicznych. Kształtowanie się i funkcjonowanie kultur narodo-

Adres do korespondencji: aszpoc@isppan.waw.pl 
wych jest związane z procesem wyodrębniania pewnych części tego uniwersum jako kultury właściwej danej grupie, co pozwala jej członkom odróżniać się od innych grup mających odmienne kultury. Kultura narodowa zatem, na przykład polska kultura narodowa, to pewna cząstka ze zbioru „wszystkie języki”, język polski i/lub cząstka obyczajów rozpoznanych jako własne (np. wigilia bożonarodzeniowa) ze zbioru „wszystkie przeszłe i obecne obyczaje”), i/lub cząstka z całego systemu sztuki identyfikowana jako sztuka własna (np. Pan Tadeusz) itd. Kulturę narodową jako cząstkę uniwersum kulturowego Kłoskowska przedstawia $\mathrm{W}$ postaci diagramu:

System kultury symbolicznej

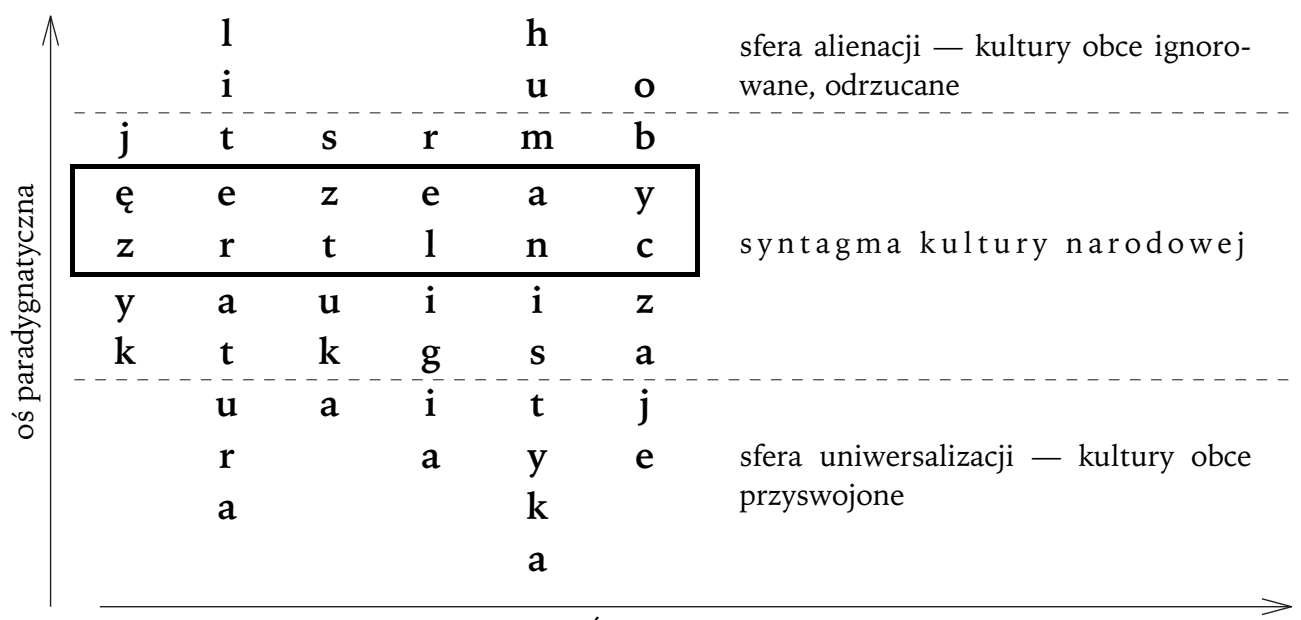

oś syntagmatyczna

Na przedstawionym diagramie (z niewielkimi skrótami jego opis cytuję tu za Kłoskowska) „kolumny pionowe oznaczają główne systemy kultury symbolicznej: język, sztukę i literaturę, wiedzę i naukę, religię, obyczaje”. Tworzą one systemy o charakterze paradygmatycznym. Są to elementy „pomyślanej lub realnej kultury pojmowanej jako wyobrażona potencjalna całość uniwersalna albo jako realna suma wszystkich cząstkowych etnicznych i narodowych systemów danego rodzaju: wszelkich religii, wszelkich języków, zbiorów obyczajów, systemów sztuk, jakie kiedykolwiek i gdziekolwiek realizowano w dziejach całej ludzkości” (Kłoskowska 1996, s. 38). Kolumny paradygmatyczne przecinają linie poziome wyodrębniające kultury narodowe. Na zewnątrz linii poziomych ograniczających zasięg kultury narodowej znajdują się: po jednej stronie strefa ignorancji, po drugiej strefa poznanych kultur innych - sfera uniwersalizacji.

Kulturę narodową w koncepcji Kłoskowskiej należy ujmować jako układ „wycinków” szczegółowych systemów kulturowych (sztuka, język, nauka, historia, obyczaj itp.) powiązanych związkami syntagmatycznymi. „W kulturo- 
wej syntagmie - czytamy w Kulturach narodowych u korzeni (Kłoskowska 1996, s. 38) - jak w językowej wypowiedzi reguły syntaktyczne wyznaczają związki pomiędzy poszczególnymi elementami”. Kłoskowska od razu jednak zaznacza, że nie ma ścisłej odpowiedniości między językoznawczym a kulturoznawczym użyciem tego terminu. Aby przybliżyć swoje rozumienie kultury narodowej, autorka odwołuje się do odnotowanej przez Ruth Benedict przypowieści Indian kopaczy o czerpaniu z nieukształtowanego żywiołu kultury własnym kubkiem nadającym dopiero kształt tej substancji (Kłoskowska 1996, s. 37). Ów żywioł kultury to uniwersum kulturowe jednostek i zbiorowości. Zawartość kubka to faktyczna kultura narodowa.

W moim przekonaniu metafora kubka $z$ opowieści indiańskiej, choć intuicyjnie zrozumiała, nie w pełni satysfakcjonuje. Kłoskowska miała trudności z określeniem relacji i związków zachodzących pomiędzy czynnikami konstytuującymi kulturę narodową. W jednej z pierwszych swych prac na ten temat pisała o syntetyzującym charakterze kultury narodowej (Kłoskowska 1990, s. 15), dopiero później, przygotowując ostatnią swoją książkę zaczęła pisać o związkach syntagmatycznych i syntagmie, ale i z tego określenia autorka nie była w pełni zadowolona. Sugerowała, że trzeba by kwestię tę jeszcze dopracować. Na swój użytek syntagmatyczność relacji zachodzących pomiędzy poszczególnymi elementami i kultury narodowej rozumiem w taki sposób, że elementy paradygmatyczne, zidentyfikowane jako kultura własna, funkcjonują nie jako izolowane cząstki, lecz jako zorganizowany system zależności i związków jako coś, co można by metaforycznie określić jako syntagmę.

Syntagmatyczność związków pomiędzy składowymi kultury narodowej rozumieć można w taki sposób, iż każdy z elementów ewokuje jeszcze jakieś inne elementy wchodzące $\mathrm{w}$ skład kultury $\mathrm{z}$ odmiennych osi paradygmatycznych. Aby objaśnić ten nieco skomplikowany wywód, posłużę się przykładem. Rzeczownik „dzień”, jeżeli zostanie włączony w strukturę syntagmatyczną, czyli stanie się z częścią zdania, ewokuje jakieś czasowniki, które w zdaniu będą pełniły funkcje orzeczenia (np. „wstaje”), jakieś przymiotniki, które w zdaniu będą przydawkami (np. „słoneczny”) itd. Analogicznie Chopin, jeżeli postrzegany jest jako element kultury narodowej, będzie ewokował inne elementy tej kultury $z$ innych, niekoniecznie bliskich sztuce, porządków paradygmatycznych, na przykład charakterystyczny dla kultury polskiej sposób obchodzenia wigilii, „polskie" krajobrazy, znaczące wydarzenia polityczne, historyczne itd. Prawdopodobnie autorka Kultur narodowych u korzeni zgodziłaby się takim ujęciem. W książce tej pisała: „Metaforycznie więc tylko traktowane pojęcie syntagmy ma uzmysłowić związki zachodzące pomiędzy poszczególnymi systemami kultury tej samej zbiorowości narodowej" (Kłoskowska 1996, s. 38).

Rdzeniem kultury narodowej jest kanon kulturowy. Przez kanon należałoby rozumieć zbiór zdarzeń, postaci i wytworów kulturowych, o których członek danej wspólnoty wiedzieć coś powinien. Osobnik, któremu nic nie mówi nazwisko Mickiewicz, dla którego Grunwald jest nazwą pustą, nawet jeżeli urodził 
się w Polsce i mówi po polsku, zostanie uznany za specyficznego, bo nieuświadomionego członka wspólnoty narodowej.

Tak w największym uproszczeniu można by przedstawić zarys koncepcji kultury narodowej Antoniny Kłoskowskiej. Przechodzę teraz do szczegółowego omawiania wybranych wątków tej koncepcji - tych, które wydały mi się ciekawe, czy to ze względów praktycznych - jako pogłębienie (samo)wiedzy o procesach zachodzących we współczesnej kulturze, czy to teoretycznych.

Kwestia pierwsza dotyczy złożonego problemu: kultura narodowa a kultura społeczeństwa narodowego. Wyjaśniam od razu, że przez społeczeństwo narodowe będę rozumiał takie (najzwyklejsze) społeczeństwo, którego członkowie są zdolni czuć się również członkami wspólnoty narodowej, co wprawdzie w kręgu kultury zachodnioeuropejskiej zdarza się dość często, ale co przecież nie jest obowiązującą regułą. Nim przejdę do omawiania tej kwestii, pozwolę sobie na kilka słów wyjaśnienia.

W Kulturach narodowych u korzeni Kłoskowska wiele miejsca poświęca różnicom między trzema fundamentalnymi wymiarami życia społecznego: narodem, państwem i społeczeństwem ${ }^{1}$. Nie wdając się tu w szczegółowe rozważania przyjmijmy, że państwo to układ instytucji (rząd, wojsko, administracja publiczna), społeczeństwo to układ grup społecznych, wreszcie naród to wspólnota kulturowa (wspólnota budująca poczucie swojej tożsamości w odwołaniu do wspólnej kultury). Zarówno państwo, jak i stan, w jakim znajduje się społeczeństwo, miały (i mają) znaczący wpływ na rozwój wspólnot narodowych. We współczesnych naukach społecznych, a zwłaszcza politycznych, dużą popularnością cieszą się te teorie narodu, w których to instytucjom państwowym lub rozwojowi społeczeństwa obywatelskiego, a nie kulturze, przypisuje się decydującą rolę w kształtowaniu wspólnot narodowych. W przywoływanej tu książce Kłoskowska (1996, s. 27-32) omawia szczegółowo te koncepcje, zwracając przy tym uwagę, że procesy narodowotwórcze nie miały jednolitego charakteru. W wypadku takich narodów jak Anglia czy Francja rola instytucji państwowych w budowaniu więzi narodowych była być może ${ }^{2}$ bardziej znacząca (pierwotna w stosunku do kultury). Inaczej w wypadku Polski, gdzie zwłaszcza po utracie państwowości - świadomość istnienia własnej kultury miała kapitalne znaczenie dla kształtowania się i funkcjonowania narodu polskiego. Wydaje się jednak, że przynajmniej w kręgu cywilizacji euroatlantyckiej rola kultury narodowej w kształtowaniu narodu w żadnym ze znanych przypad-

1 Te trzy wymiary stanowią podstawę trzech odrębnych teorii narodu. Nie będę się nimi tu zajmował, ponieważ interesuje mnie tylko kultura narodowa i w konsekwencji kulturalistyczna koncepcja narodu.

2 Używam trybu przypuszczającego, ponieważ nie jestem do tej tezy przekonany. Analiza materiałów historycznych, omawianych również przez Kłoskowską w Kulturach narodowych $u$ korzeni, wskazuje, jak się wydaje, że oba te czynniki, poczucie wspólnoty politycznej i poczucie wspólnoty kulturowej, działały jednocześnie i wzajemnie się wzmacniały. 
ków nie była marginalna. Kwestiami tymi, choć są one ważne w całokształcie poglądów Kłoskowskiej, dalej nie będę się już zajmował, gdyż zbytnio oddalałyby nas od głównego przedmiotu moich zainteresowań - kultury narodowej.

Po tej dygresji wracam do postawionego pytania: czy kultura społeczeństwa narodowego to coś innego niż kultura narodowa? Odpowiedź na to pytanie jest wręcz żenująco banalna - oczywiście, że różnica istnieje, a mimo to nawet przez osoby profesjonalnie zajmujące się problematyką narodu te dwie odmienne sfery kultury nagminnie są nierozróżniane. Mówiąc o „kulturze narodu”/,kulturze narodowej” (w takich wypadkach terminy te są mieszane) ma się na myśli kulturę tu i teraz istniejącego społeczeństwa narodowego (np. społeczeństwa polskiego). W tym wypadku „naród” rozumiany jest jako synonim „społeczeństwa”. Takie zamienne stosowanie tych terminów, zgodnie z tym, o czym pisałem wcześniej, jest całkowicie nieuprawnione. Ten typ praktyki językowej pojawia się powszechnie zapewne dlatego, że pojęcie współczesnego narodu polskiego i pojęcie współczesnego polskiego społeczeństwa narodowego mają ten sam desygnat. Postawny zatem pytanie, jak mają się do siebie kultura społeczeństwa narodowego i kultura narodowa?

Jeżeli kulturę zdefiniujemy jako zbiór respektowanych w danej grupie wartości, wzorów zachowań i norm, to w odniesieniu do współczesnych społeczeństw narodowych trudno byłoby mówić, że posiadają wspólną kulturę narodową. Obyczaje, styl życia, system wartości zawodowego żołnierza będą różniły się od stylu życia i systemu wartości rolnika czy profesora. Jeżeli łączy ich jakąś kultura (kultura narodowa właśnie), to z pewnością nie jest to kultura społeczeństwa, które w pewnych sytuacjach definiuje się także jako naród, stanowi ona co najwyżej pewną cząstkę tej kultury, w dodatku specyficznie (syntetyzująco, syntagmatycznie) zorganizowaną.

Zwrócenie uwagi na to, że kultura narodowa nie może być utożsamiana $z$ kulturą społeczeństwa narodowego (lub po prostu społeczeństwa), pozwala na sformułowanie dodatkowych pytań dotyczących jej funkcjonowania. Są to pytania o specyfikę mechanizmów kształtowania się kultury narodowej oraz o charakter więzi budowanych na podstawie doświadczania (przeżywania) tej kultury.

Jak przed chwilą wspomniałem, kultura społeczeństwa narodowego i kultura narodowa to odrębne formy kultury. Kultura społeczeństwa to zbiór norm, wzorów zachowań i wartości respektowanych przez grupy społeczne tworzące społeczeństwo narodowe. Ponieważ są to społeczeństwa składające się z wielu, odmiennych pod wieloma względami, grup społecznych, również kultura takiego społeczeństwa (np. wartości, styl życia, obyczaje itd.) jest silnie zróżnicowana; stanowi mozaikę wielu kultur, których podstawową funkcją jest różnicowanie i podtrzymywanie dystynkcji w obrębie danego społeczeństwa, a nie integrowanie (por. Bourdieu 2005).

Inaczej jest w wypadku kultury narodowej. Kultura narodowa, a zwłaszcza kanon narodowy, to pewien projekt, konstrukt, który bywa doświadczany przez 
członków wspólnoty. Kultura ogólna kształtuje się w dużym stopniu spontanicznie, jako reakcja na stymulacje płynące $z$ różnych obszarów życia społecznego. Kultura narodowa, a zwłaszcza kanon kulturowy, w o wiele większej skali kształtują się w wyniku interwencji (działań, akcji) specjalnie do tego celu wyznaczonych instytucji, autorytetów, środowisk opiniotwórczych. W jednym $z$ rozdziałów Kultur narodowych u korzeni autorka omawia historyczny proces kształtowania się kultur narodowych ${ }^{3}$. Związany jest on $z$ wyłanianiem się elit kulturowych, które $z$ jednej strony tworzyły tę kulturę, z drugiej ją kodyfikowały. Proces wyłaniania się elit kulturowych, a wraz z tym kształtowania kultur narodowych, w znaczącej skali przypada na okres renesansu. To wtedy w większości państw europejskich mamy do czynienia z rozkwitem literatury w językach narodowych, ale precedensy pojawiają się dużo wcześniej, bo już w XIII wieku, jak wykazał w Świcie narodów europejskich cytowany przez Kłoskowską Benedykt Zientara. W tych to czasach na znaczącą skalę pojawiają się różnego rodzaju działania mające na celu obronę (promocję) języka ojczystego 4 . Wątkami historycznymi dalej zajmował się nie będę. Chciałbym natomiast skupić się na ogólnych mechanizmach kształtowania kultur narodowych.

Jak już wspomniałem, dla powstania kultur narodowych konieczne jest pojawienie się instytucji uznanych w społeczeństwie za uprawnione do orzekania o tym, co, jakie elementy z ogólnego dziedzictwa są szczególnie ważne. Zestaw takich instytucji jest zmienny historycznie, same te instytucje mają charakter historyczny - pojawiają się w pewnym momencie dziejów i giną. Głosząc opinie o zaniku narodów i kultur narodowych, milcząco przyjmuje się założenie, że dotychczasowe instytucje arbitrów (kluczników) w kwestiach kultury narodowej przeżywają się i nie zostaną zastąpione żadnymi innymi. W moim przekonaniu jest to jednak kwestia otwarta, wymagająca przede wszystkim systematycznych badań.

Wspomniałem na początku, że teoria kultury narodowej Antoniny Kłoskowskiej została tak sformułowana, że otwiera perspektywy na prowadzenie systematycznych badań, których wyniki mogą weryfikować opinie formułowane czy to na podstawie obserwacji, czy to intuicji. Otóż badanie całego systemu instytucji działających w polu kultury może wnieść wiele istotnych korekt do przeważających $\mathrm{w}$ świecie nauki opinii na temat kondycji współczesnych narodów. Nie chciałbym tu sugerować kierunku takich korekt, gdyż nie dysponuję odpowiednimi badaniami. Sama Kłoskowska daleka była od głoszenia rychłego upadku narodu. W jednym z późniejszych swoich artykułów, Kultury narodowe

\footnotetext{
3 Cz. I. „Teoria, historia i antropologia narodu”, rozdz. 2. „ Perspektywa historyczna”.

4 Przykładem mogą być uchwały synodu w Łęczycy zwołanego w 1285 r. przez arcybiskupa Jakuba Świnkę nakazujące wygłaszanie kazań w języku polskim. Sformułowania, jakich tam użyto: „Ale i inne nieszczęścia pomnożyły się w kraju przez napływ tego narodu (tj. Niemców), albowiem naród polski jest przez nich uciskany, znieważany, nękany wojnami, pozbawiony chwalebnych praw i zwyczajów ojczystych", świadczą o tym, że szło o obronę godności narodowej, a nie o coś innego.
} 
wobec globalizacji a tożsamość jednostki z 1997 r., zwracała uwagę na coś, co dziś już jest oczywiste, ale wtedy jeszcze takie nie było, a mianowicie na to, że procesy globalizacji z jednej strony prowadzą do ujednolicenia kultury, ale $z$ drugiej wzmagają tendencję do akcentowania własnej odrębności. Pozostaje kwestią otwartą, czy poszukiwanie własnej odrębności lub zjawiska glokalizacji stymulują trwanie kultur narodowych, czy też przeciwnie - podkopują je, kierując zainteresowania ku bardziej kameralnym, lokalnym przestrzeniom kulturowym.

W hipotezach mówiących o słabnięciu czy zaniku kultur narodowych za jedną z ważniejszych przyczyn tego stanu rzeczy uznaje się zmiany w systemie edukacyjnym i - szerzej — systemach socjalizacji i kulturalizacji. Dawny ujednolicony system kształcenia - jego przedłużenie stanowiły ośrodki akademickie i opiniotwórcze czasopisma literackie oraz artystyczne - sprzyjał wytworzeniu stabilnych i w miarę jednorodnych kanonów kultury narodowej. Jeszcze trzydzieści-czterdzieści lat temu zakres kanonu kulturowego elity był, co prawda, szerszy od zakresu kanonu warstw niższych, ale nie był zasadniczo od niego odmienny, zawierał bowiem te same (plus pewne dodatkowe) elementy, co ten drugi. Podstawowa różnica między warstwami niższymi a wyższymi tkwiła w interpretacjach elementów kultury składających się na kanon. W dopuszczalności odmienności interpretacji poszczególnych elementów kultury narodowej i kanonu tkwi tajemnica tego, że kultura ta zdolna jest integrować i budować więzi pomiędzy osobnikami różniącymi się skądinąd stylami życia. Elementy kanonu są nosicielami dwojakiego typu wartości: ogólnej wartości „polskość” i wartości partykularnych, na przykład patriotyzmu, kultury, sprawiedliwości. Kłoskowska wielokrotnie zwracała uwagę, że kultura narodowa, by trwać, musi być obecna w doświadczeniu indywidualnym jednostek. Pisała też, że żadna jednostka nie przyswaja sobie całej kultury. Jedną ze specyficznych cech doświadczania kultury narodowej jest to, że pozwala ona na przeżycie jedności w różnorodności. Zwracając się ku kulturze narodowej, ku kanonowi, jednostki dokonują indywidualnych wyborów, hierarchizując w sobie tylko właściwy sposób kanon i dokonując dla siebie tylko (lub dla siebie i członków swojej grupy) interpretacji jego elementów. Twórczość Chopina będzie czymś innym dla krytyka muzycznego i dla urzędnika, tym niemniej obaj mogą ją postrzegać jako element kultury narodowej stymulujący ich poczucie więzi ze wspólnotą narodową.

Indywidualizująca zasada wybiórczości, innych hierarchii, a wreszcie odmiennych interpretacji kanonu, sprawia, że na ogół mamy do czynienia $z$ różnymi wersjami tej kultury, z innymi przedstawieniami „ducha narodu”, co bywa przedmiotem częstych sporów.

Czy opisane zjawiska należą bezpowrotnie do przeszłości? Zgodnie z przyjętą tu zasadą szukania inspiracji w koncepcji kultury narodowej Antoniny Kłoskowskiej, a nie pisania w jej imieniu diagnozy współczesnej kultury, pytanie pozostawiam bez odpowiedzi. Zamiast tego chciałbym powrócić do pytania 
o to, czy zmiany w systemie kulturalizacji (szeroko rozumianej edukacji) rzeczywiście prowadzą do zaniku kultur narodowych. Tym razem jednak odpowiedzi szukać będę w nieco innych obszarach.

Formułując opinię, że zmiany w systemie kulturalizacji, przede wszystkim rosnąca rola $\mathrm{w}$ tym procesie instytucji upowszechniających kulturę popularną, stanowią zagrożenie dla kultur narodowych, milcząco zakłada się, że kultura narodowa to kultura wysoka, a przynajmniej wartościowa. Z perspektywy koncepcji kultury narodowej Kłoskowskiej niepoprawność takiego założenia jest oczywista. Zamieszczony wcześniej diagram, obrazujący miejsce kultury narodowej w systemie kultury symbolicznej, zawiera wyraźną informację, że kultura narodowa to struktura zbudowana $z$ wielu cegiełek, wielu bloków. Autorka Kultur narodowych u korzeni przywołuje w tym kontekście prace Jerzego Smolicza, który badając członków wieloetnicznego społeczeństwa australijskiego wskazywał na to, że zestaw paradygmatów, z których wybiera się elementy do syntagmy kultury narodowej, i ich uhierarchizowanie mogą być różne w poszczególnych wspólnotach narodowych (Kłoskowska 1996, s. 39). Nie ulega wątpliwości, że w ostatnich dwóch dekadach sam zestaw cegiełek składających się na polską kulturę narodową, jak i ich uhierarchizowanie uległy daleko idącym przemianom. $Z$ prowadzonych przeze mnie badań wynika, że słabnie znaczenie przeszłości jako jednego z bloków tworzących kulturę narodową, podobnie dzieje się z kulturą artystyczną (zob. Szpociński 2000, 2010). Czy oznacza to zmierzch kultur narodowych? Odpowiedź na to pytanie mogłyby dać prowadzone w duchu koncepcji Kłoskowskiej badania nad morfologią kultury narodowej. Badania takie mogłyby pokazać, z jakich osi paradygmatycznych wybiera się cegiełki służące do budowy kultury narodowej. Sądzę, iż można formułować dobrze uzasadnione hipotezy, że jedną z najważniejszych osi paradygmatycznych, z których pochodzi ten budulec, jest specyficzna część kultury masowej (ale raczej nie cała kultura masowa), a mianowicie kultura związana ze sportem, a dokładniej kibicowanie, które rozumiem tu szeroko - jako zainteresowanie sportem, przeżywanie sukcesów i porażek reprezentujących Polskę zawodników, niekoniecznie zaś oglądanie meczy na stadionach. To współczesne wydarzenia sportowe i sportowcy stanowią ważny, akceptowany i szeroko rozpoznawany zbiór symboli identyfikacji narodowej.

Sportowcy wchodzą w role przodowników, zarezerwowane kiedyś dla członków tradycyjnych elit kulturowych i politycznych. O narastaniu tego zjawiska świadczy coraz częstsze pojawianie się byłych wybitnych sportowców w znaczących miejscach sfery państwowej (służebnej wobec wspólnoty narodowej) - jako posłów, senatorów, rzeczników. Sygnalizuję tu jedynie problem, który czeka na zbadanie. $\mathrm{W}$ moim przekonaniu w badaniu takim najciekawsze byłoby nie tyle potwierdzenie samej hipotezy o przejmowaniu roli liderów narodu przez gwiazdy sportu, lecz pytania o to, jak owa, istotna przecież, zmiana w morfologii kultury narodowej wpływa na kondycję samej wspólnoty narodowej; jak pojmowana jest tu ciągłość, gdzie umiejscowiony jest jej główny wektor 
(w przeszłości czy może już w przyszłości?), a wreszcie, jaki ma to wpływ na postawy wobec członków innych wspólnot kulturowych. Jest to kolejny ważny temat poruszany przez Kłoskowską w badaniach nad kulturą narodową.

Antonina Kłoskowska była przekonana, że przywiązanie do własnej kultury, troszczenie się o nią w sposób szczególny, nie musi stymulować postaw niechęci czy wrogości wobec Innych, może również działać na rzecz zbliżenia narodów. Zjawiska zbliżenia, czy sąsiedztwa kultur, przez wiele lat badała w ramach grantu „Sąsiedztwo kultur”, realizowanego wspólnie z Richardem Grathoffem. W jednym $z$ artykułów pisała: „Przekonanie o możliwości przezwyciężenia konfliktów na tle gospodarczym i politycznym przez samo zbliżenie kultur - ma charakter utopijny [...]. Kultura symboliczna może jednak przeciwdziałać totalizacji konfliktów zapobiegając przenoszeniu ich na wszystkie sfery życia" (Kłoskowska 1991, s. 20). Sednem podejmowanej tak często w jej tekstach problematyki uniwersalizacji kultury, rozumianej jako przyswojenie sobie kultur Innych (por. przedstawiony wcześniej diagram), było właśnie poszukiwanie $\mathrm{w}$ odmienności kultur czynników zbliżających, nie dzielących. Wczytanie się w teksty Kłoskowskiej pozwala wyraźnie uświadomić sobie, że koncyliacyjne funkcje kultur narodowych właściwe są nie całym tym kulturom, lecz jedynie niektórym ich elementom, a mianowicie kulturze artystycznej.

Te wątki rozwijałem w jednej ze swoich prac (Szpociński 1999). Dziedzictwo artystyczne jest bowiem tą wyjątkową dziedziną życia społecznego, w której przezwyciężona zostaje obcość innych, jest to ten obszar, w którym in n o ść pozytywna dominuje nad innością negatywną.

Warto w tym miejscu zauważyć, że integralną częścią większości kultur narodowych są jakieś $\mathrm{w}$ miarę trwałe, im tylko właściwe obrazy kultur innych narodów. Geografię świata kultur można by zatem potraktować jako szczególny element kultury narodowej. Różnice w postrzeganiu kultury francuskiej czy niemieckiej przez Polaków, Czechów czy Węgrów są konsekwencją takich a nie innych porządków $w$ ich kulturach narodowych (i stanowią ich cechę dystynktywna), a nie charakteru (,ducha”) tych innych kultur.

Pisząc, iż kultura artystyczna jest tą sferą, w której dominują pozytywne odniesienia do Innych, trzeba mieć na myśli nie to, że w wypowiedziach artystycznych inne narody, grupy etniczne religijne, rasowe i ich członkowie przedstawiani są pozytywnie, lecz to, że Inni postrzegani poprzez pryzmat ich kultury artystycznej stają się innymi-bliskimi, w przeciwieństwie do postaw wobec Innych kształtowanych przez pryzmat większości doświadczeń wyniesionych $z$ historii (w potocznym znaczeniu tego słowa) polityki czy obyczajów. Fascynacja jazzem o kilka dziesiątek lat wyprzedziła regulacje prawne znoszące dyskryminację czarnej ludności w Stanach Zjednoczonych. W takim właśnie znaczeniu można mówić o kulturze artystycznej jako sferze pozytywnych odniesień do Innych i o koncyliacyjnych funkcjach sztuki.

Pozytywne odniesienia do Innych postrzeganych przez pryzmat kultury artystycznej są związane ze specyfiką postaw zajmowanych wobec sztuki i zja- 
wisk jej towarzyszących. Przy czym sferą owych pozytywnych odniesień jest nie cała kultura artystyczna, lecz tylko te jej elementy, które funkcjonują jako dziedzictwo artystyczne, czyli takie, których podstawą upamiętnienia były wartości estetyczne (estetycznie zwaloryzowane wizje świata), a nie jakiekolwiek inne. Wartości estetyczne, w odróżnieniu do innych, mają charakter uniwersalny.

W tym miejscu pojawia się nowe pytanie i nowy problem do rozwiązania: czy zmiany zachodzące we współczesnej kulturze, które za Walterem Benjaminem (1996) można określić jako zanik auratywności kultury deprecjonujący przeżycie estetyczne, nie zagrażają funkcjom koncyliacyjnym. Zwracam uwagę, że w ujęciu Benjamina zanik aury realizuje się $\mathrm{w}$ sferze odbioru sztuki, co oznacza, że również wielkie dzieła dawnych mistrzów podlegają procesowi deestetyzacji. Jeżeli przypomnimy sobie to, o czym pisałem wcześniej, a mianowicie, że rolę przewodników narodu przejmują sportowcy, a podstawowymi symbolami zbiorowej identyfikacji stają się wydarzenia sportowe, to nadzieje na zbudowanie wolnej od konfliktów wspólnoty narodów mogą okazać się płonne.

Przedstawiłem tu tylko niewielką część tematów i problemów, które pojawiają się przy lekturze tekstów Antoniny Kłoskowskiej. Moim celem, jak zaznaczyłem na początku, nie było danie wyczerpującej analizy koncepcji kultury narodowej. Podejmując niektóre wątki, pochodzące głównie z ostatniej jej książki, chciałem jedynie zasugerować, że do tekstów autorki Kultur narodowych $u$ korzeni warto wracać, ponieważ mogą być źródłem inspiracji badawczych.

\section{BIBLIOGRAFIA}

Bejamin Walter, 1996, Dzieło sztuki $w$ dobie reprodukcji technicznej, w: Walter Benjamin, Aniot historii. Eseje, szkice, fragmenty, tłum. różni, Wydawnictwo Poznańskie, Poznań. Bourdieu Pierre, 2005, Dystynkcja. Spoteczna krytyka władzy sądzenia, tłum. Piotr Biłos, Scholar, Warszawa.

Kłoskowska Antonina, 1990, Kultury narodowe i narodowa identyfikacja. Dwoistośc funkcji, w: Antonina Kłoskowska (red.), Oblicza polskości, Uniwersytet Warszawski, Warszawa.

Kłoskowska Antonina, 1991, Sasiedztwo narodowe i uniwersalizacja kultury, „Kultura i Społeczeństwo", nr 4.

Kłoskowska Antonina, 1996, Kultury narodowe u korzeni, Wydawnictwo Naukowe PWN, Warszawa.

Kłoskowska Antonina, 1997, Kultury narodowe wobec globalizacji a tożsamość jednostki, „Kultura i Społeczeństwo”, nr 4.

Szpociński Andrzej, 1999, Inni wśród swoich. Kultury artystyczne innych narodów w kulturze Polaków, Instytut Studiów Politycznych PAN, Warszawa,

Szpociński Andrzej, 2000, Przeszłość jako tworzywo kanonu kulturowego. Kanon kultury upowszechniany $w$ informacyjnych programach telewizyjnych, w: Joanna Kurczewska (red.), Kultura narodowa i polityka, Oficyna Naukowa, Warszawa.

Szpociński Andrzej, 2010, Wspótczesna kultura historyczna, „Kultura Współczesna”, nr 1. 


\section{ANTONINA KŁOSKOWSKA'S CONCEPT OF NATIONAL CULTURE AS A SOURCE OF INSPIRATION}

Summary

The article is an attempt at contemporary interpretation of Antonina Kłoskowska's theory of culture. The Author starts with a brief summary of her concept and follows with his analysis and elaboration on a few interesting issues which are the most interesting in his opinion. They include: national culture and the culture of a national society (i.e. a society, the members of which regard themselves also as members of a national community, an essence of integrative functions of national culture and conciliative functions of artistic heritage.

\section{Key words/słowa kluczowe}

Antonina Kłoskowska; symbolic culture / kultura symboliczna; national culture / kultura narodowa 